\title{
Patients with depressive disorder, their co-morbidity, visiting rate and disability in relation to self-evaluation of physical and mental health: a cross-sectional study in family practice Kadri Suija*, Ruth Kalda and Heidi-Ingrid Maaroos
}

\author{
Address: Department of Polyclinic and Family Medicine, University of Tartu, Puusepa 1a 50406, Tartu, Estonia \\ Email: Kadri Suija* - kadri.suija@ut.ee; Ruth Kalda - ruth.kalda@ut.ee; Heidi-Ingrid Maaroos - heidi-ingrid.maaroos@ut.ee \\ * Corresponding author
}

Published: I June 2009

BMC Family Practice 2009, 10:38 doi:10.1 186/1471-2296-10-38

This article is available from: http://www.biomedcentral.com/147I-2296/I0/38

(c) 2009 Suija et al; licensee BioMed Central Ltd.

This is an Open Access article distributed under the terms of the Creative Commons Attribution License (http://creativecommons.org/licenses/by/2.0), which permits unrestricted use, distribution, and reproduction in any medium, provided the original work is properly cited.

\begin{abstract}
Background: High prevalence of depression among primary care patients has increased the need for more research in this field. The objectives of our study were to analyse how depressed patients evaluate their health; which co-morbid diseases are associated with depression; how depression influences the patients' consultation rate in family practice (FP); how disability is associated with depression; and how depression influences the patients' working ability.
\end{abstract}

Methods: A cross-sectional study, part of the PREDICT study. The study group was formed of 1094 consecutive patients from 23 FPs across Estonia, aged 18-75 years, attending a FP to consult the family doctor (FD). Occurrence of major depression during six months was estimated using the Depression Section of the Composite International Diagnostic Interview. The medical records of all patients were analysed concerning co-morbid diseases, number of visits to the FD, and disability. Every patient filled in questionnaires to assess health-related risk factors for depression, and the SF-12 Health Survey to assess functioning and the perception of health.

Results: Depression was found in $230(21 \%)$ of the patients. Depressed patients reported less

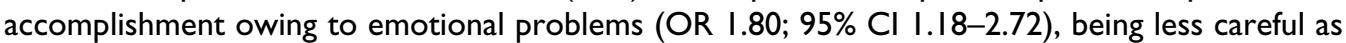

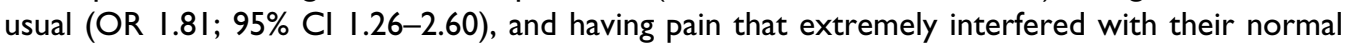
work (OR 2.50; 95\% Cl I.33-4.70) in comparison with non-depressed patients. Also depressed patients were more days on sick-leave (OR I.00; $95 \% \mathrm{Cl} \mathrm{I.00-1.01)} \mathrm{than} \mathrm{non-depressed} \mathrm{patients.}$ However, analysis of the medical records did not indicate that depressed patients consulted the FD more or had more co-morbid diagnoses than the non-depressed patients.

Conclusion: Depressed patients may have low self-reported functioning due to emotional problems, pain, and their working ability may have decreased; however, the patients of both groups have an equal number of co-morbid diagnoses and their consultation rate is similar.

\section{Background}

Patients with depressive disorder are common in family practice. About $10-18 \%$ of patients in primary care suffer from clinical depression [1-3].
Depression has been extensively studied in recent years. Several studies have shown that depressive disorder in primary care is associated with non-specific somatic symptoms, such as chronic pain and tiredness, and co- 
morbidity [4-6]. Also studies of patients with specific illnesses, e.g. cancer, diabetes mellitus, Parkinson's disease, and dementia, have shown higher rates of depression in comparison with patients without these disorders [7-9].

Depression often coexists with other psychiatric disorders. About half of patients with depression have co-morbid anxiety, and personality or alcohol use disorder [10].

Some authors have demonstrated that depression is associated with increased use of medical services, which can be partly explained by associated medical conditions $[11,12]$. Furthermore, depression is also one of the leading causes of disability in the world [13].

Several studies have shown that depressed patients have lower social and physical functioning and poorer health related quality of life than patients without depression $[11,14,15]$. However, it remains unclear whether depressed patients indeed have poorer health than nondepressed patients, or whether this is only related to their perception of having poor health $[14,15]$.

The aims of this study were to find out (1) how depressed patients themselves evaluate their health; (2) which comorbid diseases are associated with depression; (3) how depression influences the patients' consultation rate in family practice; (4) how disability is associated with depression; and (5) how depression influences the patients' working ability.

\section{Methods}

The current study is part of the PREDICT study carried out in 2003-2005 in 23 family practices across Estonia (15 in urban and 8 in rural areas) [16-18]. The study design has been described in detail elsewhere $[16,18]$. The doctors were instructed to recruit patients according to the criteria of the project $[16,18]$. The inclusion criteria were: consecutive attendees of family doctor's consultations; patients aged 18 to 75 years; patients from urban and rural areas. The exclusion criteria were non-Estonian speakers, and presence of a severe organic mental or terminal illness $[16,18]$.

After the participants had given their informed consent, a detailed interview was carried out, either at their home or at family practice centres, by specially trained interviewers within two weeks. Occurrence of major depression was assessed using the Depression Section of the Composite International Diagnostic Interview (CIDI) version 2.1, which provides a six-month depression diagnosis according to the International Classification of Diseases (ICD10) [19]. Additionally, every patient filled in questionnaires for assessment of sociodemographic and healthrelated risk factors for depression [16]. Among the ques- tionnaires used in our study was the SF-12 Health Survey (Version 1.0), which is among the most widely used instruments to assess the patients' functioning and to measure the patients' self-evaluation of their mental and physical health, and health-related quality of life [20].

To study the co-morbidity and healthcare utilization of the depressed and the non-depressed patients, we asked relevant information from their family doctors. We sent registration forms to the family doctors inquiring about the patients' co-morbid diseases by the ICD-10, number of visits to the family doctor and number of days on sickleave due to all causes between January 2003 and December 2005, and disability. The doctors were asked to fill in the registration forms using information from the patients' medical records. All registration forms distributed among the family doctors were returned.

Disability was defined in case the patient had some somatic or mental disease that limited working and he/ she had the right to receive social benefits from the social system.

Days on sick-leave were defined as days lost from work due to some illness.

\section{Statistics}

The Statistical Package for the Social Sciences (SPSS) for Windows Release 10.0.1 [21] was used for data analysis.

Standard methods (mean, standard deviation, percentages) were used for descriptive statistics. Differences between the depressed and the non-depressed patients were analysed with the Chi-Square Test and the t-test. To find out the factors associated independently with depression, we used logistic regression analysis and computed the odds ratios (OR) with 95\% confidence intervals (95\% $\mathrm{CI}$ ). In a logistic regression model, we combined and tested the variables that associated with depression, such as gender; disability; patient's self-evaluation of health in general; less accomplishment as a result of problems of physical health; limitation in work due to problems of physical health; less accomplishment as a result of emotional problems; working less carefully than usual as a result of emotional problems; having pain that interferes with normal work; health-related limitation in regular activities as moving a table or climbing stairs; and social activities interfered due to health problems; co-morbid endocrine, nutritional and metabolic disease; co-morbid mental or behavioural disorder; and number of days on sick-leave.

All tests were two-sided and statistical significance was assumed when $\mathrm{p}<0.05$. 


\section{Ethics}

The Ethics Committee of the University of Tartu approved the study.

\section{Results}

Figure 1 shows the flowchart of the study population.

The family doctors recruited 1370 patients: 195 of them declined, making contact with 75 of the patients failed, and 6 interviews were excluded due to incomplete data. Thus the final study group consisted of 1094 patients.

\section{Depression and sociodemographic factors}

The demographic data of the study group are presented in Table 1.

A six-month depressive episode occurred in 230 (21\%) patients. Significantly more female patients were depressed than male patients: of the male patients $14 \%$ and of the female patients $23 \%$ were depressed $(\mathrm{p}=$ $0.001)$.

Place of residence in the rural or in the urban area/region did not influence occurrence of depression in our study ( $p$ $=0.794)$.

The mean age of depressed patients was 44.4 years, while there was no statistical difference between the mean age of male (44.2) and female (44.4) depressed patients ( $\mathrm{p}=$ $0.179)$.

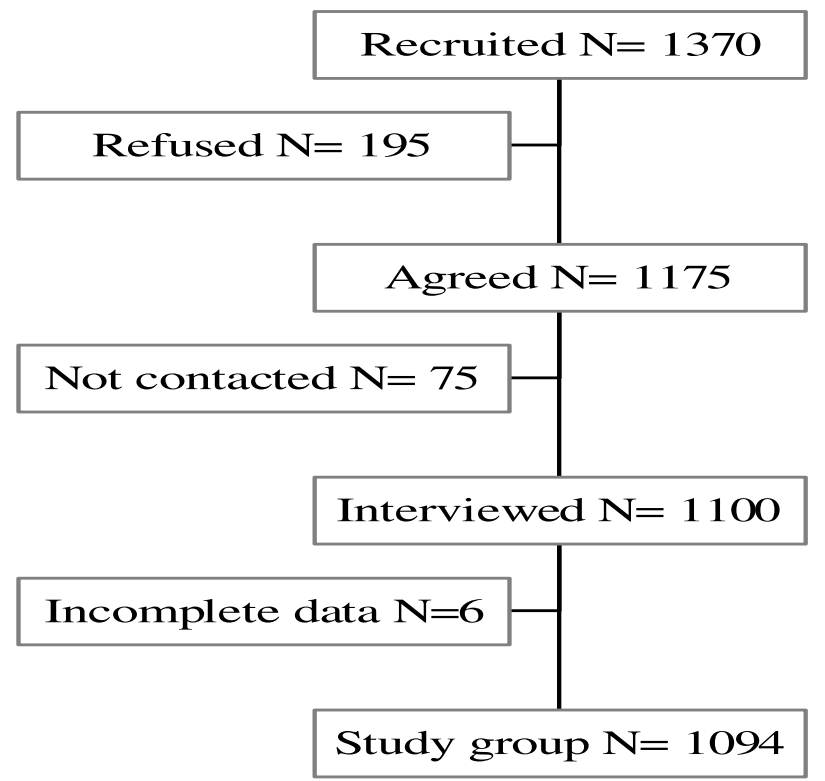

Figure I

Flowchart of the study population.
Depression was more common in patients with disability: $27 \%$ of the patients with disability versus $20 \%$ of the patients without disability were depressed during the study $(\mathrm{p}=0.034)$.

\section{Depression and patients' self-evaluation of their health}

Table 2 presents the answers of depressed and nondepressed patients to the SF-12.

We found that $22 \%$ of the depressed patients and $12 \%$ of the non-depressed patients evaluated their health in general as poor and $1 \%$ of the depressed and $3 \%$ of the nondepressed patients reported that their health in general was excellent $(\mathrm{p}=0.000)$.

Compared with non-depressed patients depressed patients reported much more limitations in their work and significantly less accomplishment owing to problems of physical and mental health during the past four weeks $(\mathrm{p}=0.000)$.

According to our analysis, depressed patients evaluated that pain interfered more with their normal work in comparison with non-depressed patients: $18 \%$ of the depressed patients and $6 \%$ of the non-depressed patients described that pain had extremely interfered with their normal work during the past four weeks $(p=0.000)$.

Depressed patients reported more limitations in such physical activities as moving a table or climbing stairs compared with non-depressed patients.

Of the depressed patients $24 \%$ and of the non-depressed patients $14 \%$ reported that their social activities were distributed by health problems all of the time or most of the time $(\mathrm{p}=0.000)$.

\section{Depression and co-morbidity}

The four most prevalent causes to consult the family doctor for all patients were diseases of the musculoskeletal, respiratory and cardiovascular systems. Mental and behavioural disorders (not depression) occupied the ninth place among the causes to consult the family doctor (Table 3).

Table 3 shows that $90 \%$ of the depressed patients and $87 \%$ of the non-depressed patients had at least one comorbid diagnosis $(\mathrm{p}=0.368)$.

There were no significant differences between the mean number of different co-morbid diagnoses for depressed and non-depressed patients $(\mathrm{p}=0.546)$ (Figure 2) but depressed patients had significantly more co-morbid psychiatric disorders (F00-F99) $(\mathrm{p}=0.042)$ and endocrine, 
Table I: Descriptive characteristics of male and female patients with or without depression assessed by the CIDI

\begin{tabular}{|c|c|c|c|c|}
\hline Characteristics & $\begin{array}{l}\text { Total } \\
\text { n (\%) }\end{array}$ & $\begin{array}{c}\text { Non-depression } \\
\text { n (\%) }\end{array}$ & $\begin{array}{c}\text { Depression } \\
\text { n (\%) }\end{array}$ & p-value \\
\hline Total & 1094 & 864 (79) & $230(2 I)$ & \\
\hline Gender & & & & 0.001 a \\
\hline Male & 291 (27) & $249(86)$ & $42(14)$ & \\
\hline Female & $803(73)$ & $615(77)$ & $188(23)$ & \\
\hline Place of residence & & & & $0.794^{a}$ \\
\hline Rural area & $263(24)$ & $206(78)$ & $57(22)$ & \\
\hline Urban area & $813(76)$ & 644 (79) & $169(21)$ & \\
\hline \multicolumn{5}{|l|}{ Age (mean \pm SD) } \\
\hline Total & $45.5 \pm 15.7$ & $45.6 \pm 16.0$ & $44.4 \pm 13.6$ & $0.179 \mathrm{~b}$ \\
\hline Male & $46.4 \pm 16.1$ & $46.8 \pm 16.4$ & $44.2 \pm 13.8$ & \\
\hline Female & $45.0 \pm 15.4$ & $45.2 \pm 15.9$ & $44.4 \pm 13.6$ & \\
\hline Disability & & & & $0.0344^{a}$ \\
\hline Yes & $199(18)$ & $146(73)$ & $53(27)$ & \\
\hline No & $882(82)$ & $708(80)$ & $174(20)$ & \\
\hline
\end{tabular}

aDifferences were analysed by the Chi-squared test.

bDifferences were analysed by the t-test.

Table 2: Depressed and the non-depressed patients' self-evaluation of their health assessed by the SF-12

\begin{tabular}{|c|c|c|c|}
\hline Answers & $\begin{array}{c}\text { Non-depression } \\
\text { n (\%) }\end{array}$ & $\begin{array}{c}\text { Depression } \\
\text { n (\%) }\end{array}$ & p-value \\
\hline \multicolumn{4}{|l|}{ Health in general } \\
\hline Excellent & $25(3)$ & $3(1)$ & $0.000 \mathrm{a}$ \\
\hline Very good & $139(16)$ & $21(9)$ & \\
\hline Good & $289(34)$ & $53(23)$ & \\
\hline Fair & $302(35)$ & $101(45)$ & \\
\hline Poor & $106(12)$ & $50(22)$ & \\
\hline Accomplished less as a result of problems of physical health & $389(45)$ & $154(67)$ & $0.000 \mathrm{a}$ \\
\hline Limitation in work as a result of problems of physical health & $423(49)$ & $165(72)$ & 0.000 a \\
\hline Accomplished less as a result of emotional problems & $396(46)$ & $172(75)$ & $0.000 \mathrm{a}$ \\
\hline Less careful than usual as a result of emotional problems & $301(35)$ & $|4|(6 \mid)$ & $0.000 \mathrm{a}$ \\
\hline \multicolumn{4}{|l|}{ Normal work interfered with by pain } \\
\hline Not at all & $283(33)$ & $43(19)$ & $0.000 \mathrm{a}$ \\
\hline Slightly & $262(30)$ & $59(26)$ & \\
\hline Moderately & $130(15)$ & $37(16)$ & \\
\hline Quite a bit & $135(16)$ & $49(21)$ & \\
\hline Extremely & $53(6)$ & $42(18)$ & \\
\hline \multicolumn{4}{|l|}{ Limitations as moving a table due to health } \\
\hline Limited a lot & $47(5)$ & $21(9)$ & $0.005^{a}$ \\
\hline Limited a little & $168(20)$ & $61(27)$ & \\
\hline Not limited at all & $649(75)$ & $148(64)$ & \\
\hline \multicolumn{4}{|l|}{ Limitations in climbing several stairs due to health } \\
\hline Limited a lot & $68(8)$ & $27(12)$ & $0.023^{a}$ \\
\hline Limited a little & $231(27)$ & $74(32)$ & \\
\hline Not limited at all & $565(65)$ & $128(56)$ & \\
\hline \multicolumn{4}{|l|}{ Social activities interfered with by health } \\
\hline All of the time & $23(3)$ & $12(5)$ & $0.000 \mathrm{a}$ \\
\hline Most of the time & $94(I I)$ & $43(19)$ & \\
\hline Some of the time & $201(23)$ & $57(25)$ & \\
\hline A little of the time & $214(25)$ & $61(26)$ & \\
\hline None of the time & $332(38)$ & $57(25)$ & \\
\hline
\end{tabular}

aDifferences were analysed by the Chi-squared test. 
Table 3: Depression and prevalence of co morbid diagnoses by the ICD- 10

\begin{tabular}{|c|c|c|c|c|}
\hline Diagnosis by ICD-I 0 & $\underset{n}{\text { Total number of cases }}$ & $\begin{array}{c}\text { Non-depression } \\
\mathrm{n}(\% \text { of non-depressed })\end{array}$ & $\begin{array}{c}\text { Depression } \\
\mathrm{n}(\% \text { of depressed })\end{array}$ & p-value \\
\hline $\begin{array}{l}\text { Diseases of the musculoskeletal system and the connective } \\
\text { tissue }\end{array}$ & 483 & $384(45)$ & $99(44)$ & 0.707 a \\
\hline Diseases of the respiratory system & 460 & $368(43)$ & $92(4 I)$ & 0.497 a \\
\hline Diseases of the cardiovascular system & 395 & $316(37)$ & $79(35)$ & 0.587 a \\
\hline Diseases of the digestive system & 196 & $158(17)$ & $38(17)$ & $0.562^{a}$ \\
\hline Endocrine, nutritional and metabolic diseases & 151 & $129(15)$ & $22(10)$ & $0.040^{a}$ \\
\hline Diseases of the genitourinary system & 144 & $105(12)$ & $39(17)$ & $0.062^{a}$ \\
\hline Certain infectious and parasitic diseases & 139 & $118(14)$ & $21(9)$ & 0.074 a \\
\hline Diseases of the skin and subcutaneous tissue & 135 & $113(13)$ & $22(10)$ & $0.175^{a}$ \\
\hline Mental and behavioural disorders & 119 & $85(10)$ & $34(15)$ & $0.042^{a}$ \\
\hline Diseases of the nervous system & 94 & $70(8)$ & $24(11)$ & 0.289 a \\
\hline $\begin{array}{l}\text { Symptoms, signs and abnormal clinical and laboratory findings } \\
\text { not classified elsewhere }\end{array}$ & 93 & $67(8)$ & $26(11)$ & 0.109 a \\
\hline Diseases of the ear and mastoid process & 65 & $53(6)$ & $12(5)$ & 0.753 a \\
\hline $\begin{array}{l}\text { Injury, poisoning and certain other consequences of external } \\
\text { causes }\end{array}$ & 51 & $41(5)$ & $10(4)$ & $1.000 \mathrm{a}$ \\
\hline Neoplasms & 39 & $30(3)$ & $9(4)$ & 0.693 a \\
\hline Any co-morbid diagnosis & 960 & $754(87)$ & $206(90)$ & $0.368^{a}$ \\
\hline
\end{tabular}

aDifferences were analysed by the Chi-squared test.

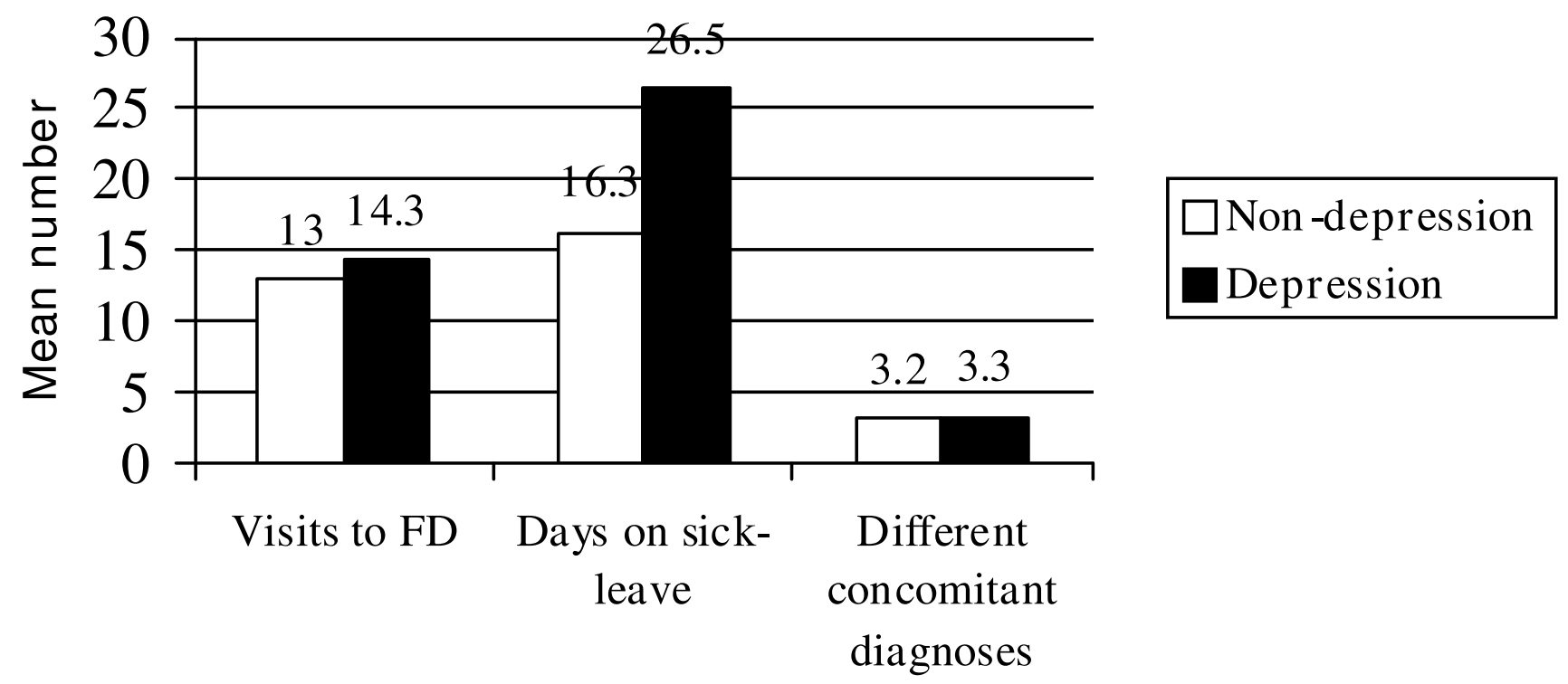

Figure 2

Mean number of visits to the FD, days on sick-leave and different co-morbid diagnoses of patients with nondepression and patients with depression. Differences were analysed by the t-test. Mean number of visits to the FD, $p=$ 0.156 . Mean number of days on sick-leave, $p=0.002$. Mean number of different co-morbid diagnoses, $p=0.546$. 
nutritional and metabolic disorders (E00-E90) ( $\mathrm{p}=$ 0.040) than non-depressed patients (Table 3).

\section{Depression and number of visits to the family doctor and days on sick-leave}

Figure 2 illustrates associations between the patients number of visits to the family doctor, number of days on sick-leave and number of different diagnoses by the ICD10.

Depressed patients consulted their family doctor slightly more than non-depressed patients but the difference was not significant $(\mathrm{p}=0.156)$.

However, depressed patients were significantly longer on sick-leave compared with non-depressed patients (26.5 and 16.3 days, respectively) $(\mathrm{p}=0.002)$.

\section{Depression and factors associated with depression in logistic regression analysis}

In logistic regression analysis four variables were independently associated with depression. These were less accomplishment as a result of emotional problems (OR $1.80 ; 95 \%$ CI 1.18-2.72), being less careful than usual as a result of some emotional problems (OR 1.81; 95\% CI 1.26-2.60), having pain that extremely interfered with work (OR 2.50; 95\% CI 1.33-4.70), and being more days on sick-leave (OR 1.00; 95\% CI 1.00-1.01) (Table 4).

\section{Discussion}

The main finding of this study is establishment of absence of association between depression and co-morbid diseases. Furthermore, analysis of the patients' medical records showed that depressed patients had as many concomitant diagnoses as non-depressed patients and they consulted the family doctor as often as non-depressed patients did.
To our knowledge, this is a new finding. Earlier studies have shown that co-morbidity is more common among depressed than non-depressed patients $[1,22,23]$, and that depressed patients consult the doctor more frequently than non-depressed patients $[1,18,24]$.

This discrepancy can be related to differences in the methodology used in the above studies and in our study. Firstly, the sources of information about co-morbidity and consultation rate were different: to prevent any information bias, we inquired the family doctors and not the patients about these variables $[1,22,23]$. Secondly, the instruments used to assess depression were also different: some studies employed screening instruments [22,23] and not diagnostic instruments such as CIDI. Thirdly, the length of the study period can also play a role: we registered all co-morbid diagnoses and visits to the family doctor for a period of three years while in other studies the pertinent period was only six months [18]. Indeed, depressed patients consult the doctor more often during an illness episode the duration of which is usually not more than six months so that after recovery, consultation rate will decrease. Cultural and organizational differences may also affect consultation rate. For example, in Estonia it is possible to consult the psychiatrist without referral. However, according to an earlier study, 98\% of family doctors in Estonia treat depressed patients on their own [25]. Further studies are necessary to clarify all these aspects.

As there were no differences in the number of co-morbid diagnoses between depressed and non-depressed patients in our study, we can not claim that patients with co-morbid illnesses are more likely to have depression. Based on our findings, depression should be considered an independent serious disease that requires also an independent approach. Moreover, the impact of depression should not

Table 4: Association of different variables with depression in logistic regression analysis

\begin{tabular}{|c|c|c|}
\hline Variable & Odds ratio (OR) & $95 \%$ confidence interval $(95 \% \mathrm{Cl})$ \\
\hline \multicolumn{3}{|c|}{ Accomplished less as a result of emotional problems (SF-12) } \\
\hline Yes & 1.80 & $1.18-2.72$ \\
\hline No & 1.0 & \\
\hline \multicolumn{3}{|c|}{ Less careful than usual as result of any emotional problems (SF-I2) } \\
\hline Yes & 1.81 & $1.26-2.60$ \\
\hline No & 1.0 & \\
\hline \multicolumn{3}{|c|}{ Normal work interfered with by pain (SF-12) } \\
\hline Not at all & 1.0 & \\
\hline Slightly & 1.24 & $0.77-1.99$ \\
\hline Moderately & 1.23 & $0.70-2.17$ \\
\hline Quite a bit & 1.23 & $0.70-2.15$ \\
\hline Extremely & 2.50 & $1.33-4.70$ \\
\hline Days on sick-leave & 1.00 & $1.00-1.01$ \\
\hline
\end{tabular}


be underestimated when it occurs as a concomitant disease.

As almost all of our patients (88\%) had some co-morbid diagnosis, irrespective of the fact whether they had depression or not, we can conclude that co-morbidity as a phenomenon is common in family practice. A similar prevalence of co-morbidity among primary care patients was found by Vuorilehto et al [5].

From the clinical point of view, it is important to point out that as almost all family practice attendees have some co-morbid diagnosis, their management is a challenge for the family doctor. According to van Weel et al., "co-morbidity is a regular feature of general practice and dealing with co-morbidity needs a patient-centred rather than a disease-oriented approach" [26].

In this study the factors that were separately associated with depression, such as gender, disability, health in general, limitations in work as a result of problems of physical health, social activities disturbed by health problems, co-morbid endocrine and mental disorders, were not associated with depression in a combined multifactor model.

Only four factors were independently associated with depression: less accomplishment as a result of emotional problems, being less careful than usual as a result of emotional problems, having pain that extremely interfered with work, and being more days on sick-leave.

Depressed patients reported that they accomplished less and were less careful as a result of emotional problems these being typical emotional symptoms of depression.

Additionally, depressed patients reported having more pain than non-depressed patients. There is evidence that pain and depression are often associated $[12,27]$. Thus, from the practical point of view, it is important to acknowledge that, besides information about specific emotional symptoms, also information about non-specific symptoms such as pain should be obtained from depressed patients.

According to our results, depressed patients were more days on sick-leave than non-depressed patients. Previous studies have also shown that psychiatric problems are among the most common diagnostic groups accounting for high sickness absence [22,28].

It should be emphasised that the strength of our study is the fact that the study group was formed of consecutive general practice attendees but not simply of patients with emotional or psychiatric symptoms. A better knowledge of the problems of consecutive patients is important for the doctors' readiness to have necessary skills for management of patients with different problems in family practice.

The other strengths are a quite large and representative study group (1094 primary care patients), use of the reliable diagnostic instrument CIDI in assessment of depression, and the patients' and the family doctors' high motivation to contribute to the study $(80 \%$ of the recruited patients completed the study).

The limitations of this study are lack of information about the reasons for being on sick-leave and about the number of days on sick-leave due to depression. On the other hand, establishment that depression is associated with high sickness absence seems more important than finding out specific reasons for being on sick-leave. In addition, the cross-sectional nature of the study makes it impossible to determine causality between depression and co-morbidity as well as between consultation rate and disability. However, our purpose was to compare the depressed and the non-depressed patients' co-morbidity, disability, and consultation rate rather than to study the mechanisms of the relationship.

\section{Conclusion}

The results of this study show that depressed patients have low self-reported functioning related to emotional problems; they also report pain and their working ability is decreased. Yet, depressed patients consulted the family doctor as often as did patients without depression and the patients of both groups had an equal number of co-morbid diagnoses.

\section{Abbreviations}

CIDI: Composite International Diagnostic Interview; FD: family doctor; FP: family practice; ICD-10: International Classification of Diseases.

\section{Competing interests}

All authors declare that they have no competing interests related to the present study.

This study was financially supported by the Estonian Science Foundation (grants number 5696 and 7596) and by targeted financing (TARPO 0821).

\section{Authors' contributions}

KS participated in the designing of the study, collected and analysed the data and completed the manuscript. RK and HIM participated in the designing of the study, collected and analysed the data, and approved the final manuscript. 


\section{Acknowledgements}

The authors express their gratitude to the PREDICT group.

\section{References}

I. Al-Windi A: Depression in general practice. Nord J Psychiatry 2005, 59:272-277.

2. Salokangas RKR, Poutanen O, Stengard E: Prevalence of depression among patients seen in community health centres and community mental health centres. Acta Psychiatr Scand 1996, 93:427-433.

3. Goldberg DP, Lecrubier Y: Form and frequency of mental disorders across centres. In Mental illness in general health care: an international study Edited by: Üstün TB, Sartorius N. Chichester: John Wiley \& Sons on behalf of WHO; 1995:323-334.

4. Simon GE, VonKorff M, Piccinelli M, Fulleron C, Ormel J: An International Study of the Relation between Somatic Symptoms and Depression. The N Engl J of Med 1999, 34 I:|329-I335.

5. Vuorilehto M, Melartin T, Isometsä E: Depressive disorders in primary care: recurrent, chronic, and co-morbid. Psychol Med 2005, 35:673-682.

6. Ellis GK, Robinson JA, Crawford GB: When symptoms of disease overlap with symptoms of depression. Aust Fam Physician 2006, 35:647-649.

7. Massie MJ: Prevalence of depression in patients with cancer. of the Nat Cancer Institute Monographs 2004, 32:57-7I.

8. Anderson RJ, Freedland KE, Clouse RE, Lustman PJ: The prevalence of co morbid depression in adults with diabetes: a meta-analysis. Diabetes care 200I, 24:1069-78.

9. Nuyen J, Schellevis FG, Satariano WA, Spreeuwenberg PM, Birkner MD, Bos GA van den, Groenewegen PP: Comorbidity was associated with neurologic and psychiatric disease: $A$ general practice-based controlled study. I Clin Epidemiol 2006, 59: I 274- I 284.

10. Melartin TK, Rytsälä HJ, Leskelä US, Lestelä-Mielonen PS, Sokero TP, Isometsä ET: Current comorbidity of psychiatric disorders among DSM-IV major depressive disorder patients in psychiatric care in the Vantaa Depression Study. J Clin Psychiatry 2002, 63: 126-34.

II. Herrman H, Patrick DL, Diehr P, Martin ML, Fleck M, Simon GE, Buesching DP: Longitudinal investigation of depression outcomes in primary care in six countries: the LIDO Study. Functional status, health service use and treatment of people with depressive symptoms. Psychol Med 2002, 32:889-902.

12. Hitchcock PN, Williams JW, Unützer J, Worchel J, Lee S, Cornell J, Katon W, Harpole LH, Hunkeler E: Depression and comorbid illness in elderly primary care patients: impact on multiple domains of health status and well-being. Ann Fam Med 2004 2:555-562.

13. World Health Organization: The global burden of disease: 2004 update 2008 [http://www.who.int/healthinfo/global burden disease GBD report 2004update full.pdf]. Geneva: WHO Press

14. Wells KB, Sherbourne CD: Functioning and utility for current health of patients with depression or chronic medical conditions in managed, primary care practices. Arch Gen psychiatry 1999, 56:897-904.

15. Brenes GA: Anxiety, Depression, and Quality of Life in Primary Care Patients. Prim Care Companion J Clin Psychiatry 2007, 9:437-443.

16. King M, Weich S, Torres F, Svab I, Maaroos H-I, Neeleman J, Xavier M, Morris R, Walker C, Bellon JA, Moreno B, Rotar D, Rifel J, Aluoja A, Kalda R, Geerling M, Carraca I, Caldas de Almeida M, Vicente B Saldivia S, Rioseco P, Nazareth I: Prediction of depression in European general practice attendees: the PREDICT study. BMC Public Health 2006, 6:6

17. Ööpik P, Aluoja A, Kalda R, Maaroos HI: Screening for depression in primary care. Fam Pract 2006, 23:693-8.

18. King M, Nazareth I, Levy G, Walker C, Morris R, Weich S, Bellon-Saameno JA, Moreno B, Svab I, Rotar C, Rifel J, Maaroos HI, Aluoja A Kalda R, Neeleman J, Geerling MI, Xavier M, de Almeida MC, Correa B, Torres-Gonzalez F: Prevalence of common mental disorders in general practice attendees across Europe. $\mathrm{Br} J$ of Psychiatry 2008, 192:362-367.

19. World Health Organisation: Composite International Diagnostic Interview (CIDI) Version 2.I Geneva: WHO; 1997.
20. Ware J Jr, Kosinski M, Keller SD: A I 2-Item Short-Form Health Survey: construction of scales and preliminary tests of reliability and validity. Med Care 1999, 34:220-33.

21. SPSS for Windows Rel. 10.0.1. Chicago: SPSS Inc; 1999.

22. Shvartzman P, Weiner Z, Vardy D, Friger M, Sherf M, Biderman A: Health services utilization by depressive patients identified by the MINI questionnaire in a primary care setting. Scand J Prim Health Care 2005, 23:18-25.

23. Stordal E, Bjelland I, Dahl A, Mykletun A: Anxiety and depression in individuals with somatic health problems. The Nord-Trondelag Health Study (HUNT). Scand J Prim Health Care 2003, 21:|36-4|.

24. Karlsson $H$, Lehtinen $V$, Joukamaa $M$ : Psychiatric morbidity among frequent attender patients in primary care. Gen Hosp Psychiatry 1995, I 7:19-25.

25. Ööpik P, Aluoja A, Kalda R, Maaroos HI: Family doctors' problems and motivating factors in management of depression. BMC Family Practice 2006, 7:64.

26. van Weel C, Schellevis FG: Comorbidity and guidelines: conflicting interests. Lancet 2006, 367:550-55I.

27. Bair MJ, Robinson RL, Katon W, Kroenke K: Depression and pain comorbidity. Arch Int Med 2003, I 63:2433-45.

28. Hensing G, Andersson L, Brage S: Increase in sickness absence with psychiatric diagnosis in Norway: a general population based epidemiologic study of age, gender and regional distribution. BMC Medicine 2006, 4: 19

\section{Pre-publication history}

The pre-publication history for this paper can be accessed here:

http://www.biomedcentral.com/1471-2296/10/38/pre pub

Publish with BioMed Central and every scientist can read your work free of charge

"BioMed Central will be the most significant development for disseminating the results of biomedical research in our lifetime. "

Sir Paul Nurse, Cancer Research UK

Your research papers will be:

- available free of charge to the entire biomedical community

- peer reviewed and published immediately upon acceptance

- cited in PubMed and archived on PubMed Central

- yours - you keep the copyright
BiolMedcentral 